\title{
A Rare Case of Giant Ovarian Serous Cystadenoma presenting as Psuedo-Meigs Syndrome
}

\section{Richmond Ronald Gomes}

Associate Professor of Medicine, Ad-din Women's Medical College Hospital, Dhaka, Bangladesh.

Corresponding Author: Richmond Ronald Gomes, Associate Professor of Medicine, Ad-din Women's Medical College Hospital, Dhaka, Bangladesh.

Received date: January 12, 2021; Accepted date: March 01, 2021; Published date: March 12,2021

Citation: Richmond R. Gomes (2021) A Rare Case of Giant Ovarian Serous Cystadenoma presenting as Psuedo-Meigs Syndrome. J Obstetrics Gynecology and Reproductive Sciences 5(2): DOI: 10.31579/2578-8965/056

Copyright: () 2021, Richmond Ronald Gomes, This is an open access article distributed under the Creative Commons Attribution License, which permits unrestricted use, distribution, and reproduction in any medium, provided the original work is properly cited.

\begin{abstract}
Meigs' syndrome is a rare condition characterized by the presence of a benign fibroma of the ovary, ascites and pleural effusion. Other benign cysts of the ovary (such as struma ovarii, mucinous cystadenoma, serous cystadenoma and teratomas), leiomyoma of the uterus, and secondary metastatic tumours to ovary if associated with hydro thorax and ascites are referred to as "Pseudo-Meigs" syndrome. It very uncommon and diagnosis is made difficult by symptoms that usually mimic disseminated malignancy or tuberculosis. The gold standard treatment is laparotomy and, by definition of the syndrome, after tumor removal, the symptoms resolves and the patients become asymptomatic. We presented an 18 years old girl with giant ovarian serous cystadenoma with associated pseudo-meigs syndrome, successfully managed in a low resources setting.
\end{abstract}

Key Words: meigs, pseudo-meigs, serous cystadenoma, hydrothorax, ascites

\section{Introduction}

Meigs' syndrome is diagnosed based on a triad of an ovarian fibroma, pleural effusion and ascites. It resolves spontaneously after the resection of the fibroma [1]. In 1852, Blin published the description of an ovarian fibroma with abdominal effusion in the Société de Biology de Paris (cited by Lallemand) [2]. A Demons of Bordeaux, France, gave a report to the Société de Chirurgie de Paris in 1887, that nine of 50 patients with ovarian cysts were cured of their ascites and hydrothorax by removal of the adnexal cyst. In 1937, Joe Vincent Meigs (1892-1963), an American professor of the Harvard Medical School of Gynaecology drew widespread attention of the medical profession to the syndrome [3]. Meigs used seven cases to highlight the association between a fibroma of the ovary, ascites, and hydrothorax. It was coined as Meigs' syndrome in 1937 by Rhodes and Terrell [4].

The following four characteristics were selected by Meigs in 1945 to define the syndrome:

- The tumor is a benign fibroma or a fibroma like tumor of the ovary (such as thecoma and granulosa cell tumors)

- Ascites

- $\quad$ Pleural effusion(s)

- Removal of tumor must cure the patient. [5]

Other benign cysts of the ovary (such as struma ovarii, mucinous cystadenoma, serous cystadenoma and teratomas), leiomyoma of the uterus, and secondary metastatic tumours to ovary if associated with hydro thorax are referred to as 'Pseudo-Meigs" syndrome. .[6]

An atypical case of Meigs' syndrome was reported in 1990 by Martin, et al. .[7] presenting as bilateral sanguineous pleural effusion without ascites in a woman with a granulosa cell tumor.

We presented a giant ovarian serous cystadenoma with associated pseudo-Meigs syndrome, successfully managed in a low resources setting.

\section{Case Report}

Ms. Sharmin, a 18 years old unmarried student presented to the department of Medicine, Ad-din Women's Medical College Hospital with the complaints of gradual distension of abdomen with dull aching lower abdominal pain and feeling of shortness of breath for last 2 months. She denied any fever, chest pain, cough, weight loss or altered bowel habit. Her menstrual history was normal. She had no history of exposure with patient with active tuberculosis. She was vaccinated as per EPI schedule. Past medical and surgical history were insignificant. On general examination she was of average build with mild pallor. Jaundice, cyanosis, clubbing and edema were absent. Her pulse rate was 88 / minute, blood pressure - $110 / 76 \mathrm{~mm}$ of $\mathrm{Hg}$, respiratory rate $24 /$ minute and temperature normal. Breast examination revealed no abnormalities. Respiratory system examination revealed a stony dullness over right chest wall from $6^{\text {th }}$ intercostal space downwards. Breath sounds were diminished on the right side over the same area. There were no crepitations or rhonchi. The cardiovascular system examination showed no adventitious sounds with $\mathrm{S} 1$ and $\mathrm{S} 2$ being normally audible. 
Abdominal inspection revealed fullness of whole abdomen without any prominent veins or distortion of the umbilicus. No mass could be palpated but there was tenderness in the right iliac fossa and part of the hypogastrium. Liver, spleen, and inguinal lymph nodes were not palpable. On percussion there was shifting dullness due to free fluid. Auscultation revealed normal intestinal peristaltic sounds. Vaginal examination showed a right sided solid mass of about $20 \mathrm{~cm}$ size separate from the normal sized uterus. Other systemic examinations revealed no abnormalities.

Routine investigations including complete hemogram, blood sugar, blood urea, s. creatinine, s. albumin, s. amylase, s .lipase, liver function tests and electrolytes, viral markers (HBsAg, Anti HCV) were within normal limits. Chest x-ray showed right sided pleural effusion (Figure 1). MRI of abdomen revealed huge cystic lesion measuring about $18 \mathrm{~cm} \times 19 \mathrm{~cm} \times 7 \mathrm{~cm}$, arising from right adnexal region with moderate ascites and moderate right sided pleural effusion (Figure 2, figure 3 and figure 4). Paracentesis was done. Ascitic fluid study revealed exudative fluid with protein $3.9 \mathrm{gm} / \mathrm{dl}$. Gram stain and malignant cells in ascetic fluid were negative. ADA (adenosine deaminase) was normal of $8.68 \mathrm{U} / \mathrm{L}$ (normal <25 U/L). CA-125 level was mildly raised with $54.5 \mathrm{U} / \mathrm{ml}$ (normal upto $35 \mathrm{U} / \mathrm{ml}$ ). She underwent exploratory laparotomy under general anesthesia on 2nd July, 2003. On opening the abdomen by right infraumbilical paramedian incision, plenty of deep straw colored fluid came out of the peritoneal cavity. A $18 \mathrm{~cm}$ x $19 \mathrm{~cm}$ sized cystic, tumor arising from the right ovary and adherent omentum was detected (figure 5). Uterus was normal in size. A decision for right salpingo oophorectomy was taken, for which prior consent had been taken from both the patient and her husband if the necessity arose. Exploration of the peritoneal cavity did not show any palpable lymph node or other metastasis. One unit of blood was transfused during surgery. Postoperatively, breath sounds reappeared upto the $4^{\text {th }}$ intercostals space on the right side from the 2 nd day and up to the base of both the lungs from the 8th postoperative day.
Histopathology revealed cyst wall lined by cuboidal epithelium supported by fibrocollagenous tissue suggestive of serous cystadenoma with no evidence of malignancy (Figure-6). Attached fallopian tube was unremarkable.

The patient was discharged on $11^{\text {th }}$ postoperative day in a healthy condition. She came for follow up after 6 weeks with a repeat abdominal USG and chest $\mathrm{X}$ ray which showed complete disappearance of the ascites and right sided pleural effusion.

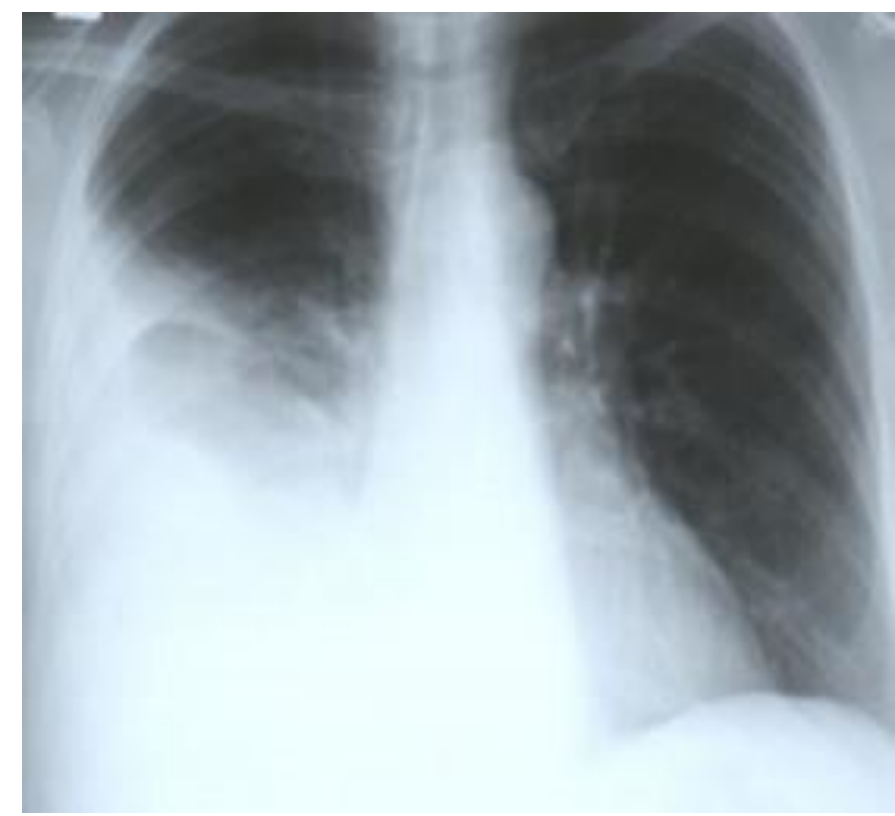

Figure 1: Showing right sided pleural effusion
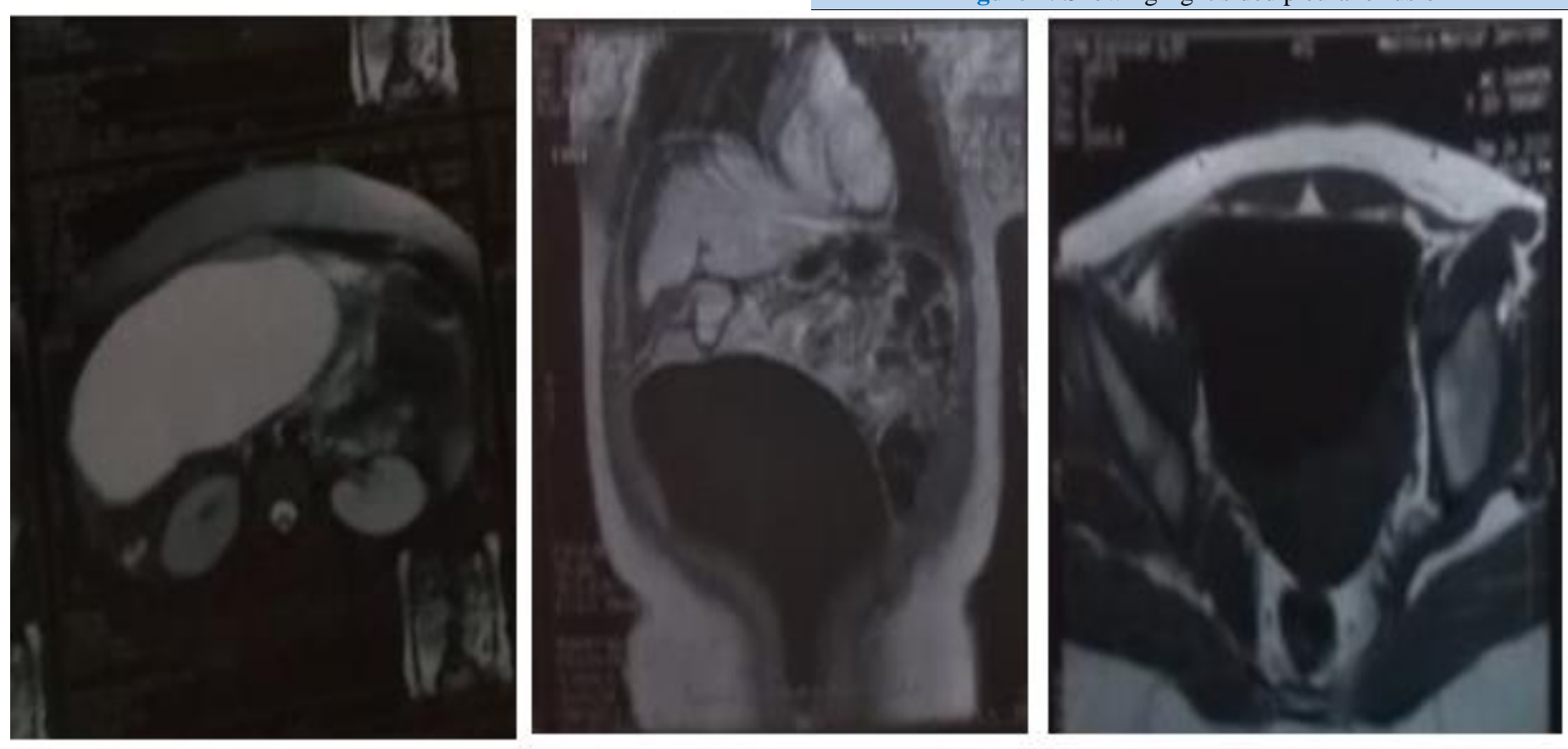

Figure 2, 3 and 4. Showing huge cystic mass arising from right adnexal region with ascites 

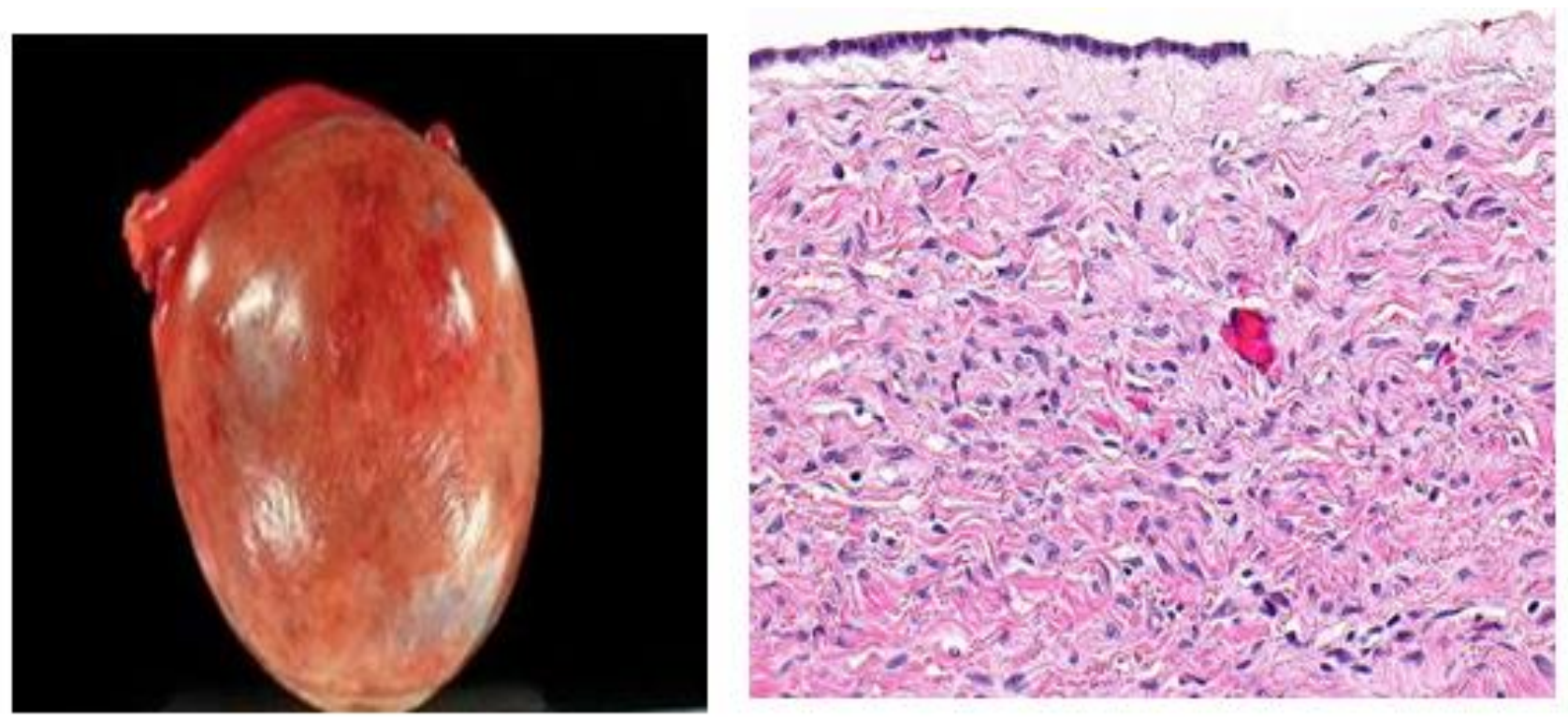

Figure 5 and 6: Serous Cystadenoma and histology of the tumor showing the cystic space is at the top of the image. Ovarian parenchyma is seen at the bottom right. H\&E stain.

\section{Discussion}

The combination of adnexal mass with pleural effusion and ascites in our case raised suspicion for Meigs' syndrome. This syndrome is a rare disorder characterized by pleural effusion and ascites in patients with ovarian fibroma or fibroma-like tumors.[8] . It was first described in 1887 by Demons, and later in 1937 by Meigs, who arrived at the same findings about association of pleural effusion, ascites, and benign ovarian fibroma. Hence, this syndrome is also known as Demons-Meigs' syndrome.[9] . On the other hand, benign tumors of the ovary (other than fibromas) and ovarian malignancies, such as mature teratomas, mucinous cystadenoma, serous cystadenoma and struma ovarii, can also be associated with pleural effusions and ascites but they are categorized as pseudo-Meigs' syndrome.[6] .

The pleurae are a structure of mesodermic origin that consists of two layers, denominated visceral and parietal layers. Both pleural layers unite in the base of the lung, leaving a space between each called the pleural cavity. A continuous process exists of filtration of liquid from the capillary vessels to the space subpleural, and give there to the cavity pleural. This process depends on the balance of hydrostatic and coloidosmotic pressures in both spaces, according to Starling's law, giving place to the presence of a minimal quantity of liquid in the physiologic virtual cavity. .[11] The pleural effusion in the cases of ovarian tumors, usually corresponds to an exudate because the liquid moves from the peritoneal cavity to the pleural cavity through diaphragmatic defects or lymphatic channels. It is generally located in the right and can be massive on occasions, with biochemical or cellular unspecific characteristics of the liquid.

Ovarian serous cystadenoma, also (less precisely) known as serous cystadenoma, is the most common ovarian neoplasm, representing $20 \%$ of ovarian neoplasms, and is benign [10]

It has a very superficial resemblance to the most common type of ovarian cancer (serous carcinoma of the ovary) under the microscope; however, .[1] it is virtually impossible to mix-up with its malignant counterpart (serous carcinoma), and [2] does not share genetic traits of indeterminate serous tumors, also called serous borderline tumors, that may transform into serous carcinoma [11]
Etiology of ascites has been explained by following mechanisms -

- Partial torsion of the ovarian vascular pedicle leading to venous engorgement and transudation (weeping of serous fluid from the tumor), which enters the pleural space through the diaphragmatic lymphatics. .[13] or through defects in the diaphragm which are more common on the right .[12] .

- Exudation from the peritoneum because of mechanical by the hard heavy mobile tumor (most likely) .[12] .

- $\quad$ Degeneration of the adenoma .[12] .

- Changes in the capsular veins of the adenoma .[12] .

- $\quad$ Probable active secretion by the tumor.[12] .

Vascular endothelial growth factor (VEGF) that raises capillary permeability is also reported to be associated with formation of pleural and peritoneal fluid. Ishiko et al. reported a significant difference between the VEGF levels in the pleural and peritoneal fluid before and after tumor removal in patients with Meigs' or pseudo-meigs syndrome.[14]. The size of the pleural effusion is largely independent of the amount of ascites. The connection between the pelvic tumor and ascites is confirmed by the rapid resolution of abdominal and pleural fluid after removal of the tumor.

The most common presenting symptoms are dyspnea (due to pleural effusion), fatigue and weight loss and most of the patients initially referred to the general practitioner or chest physicians' $[15,16]$.

The differential diagnosis for the presenting signs and symptoms include malignant ovarian tumor, other cancers including bowel and lung, nephrotic syndrome, congestive cardiac failure, liver cirrhosis and tuberculosis.

In spite of the valuable contribution of medical imaging techniques, the presumptive diagnosis of Meigs' or peuso-Meigs syndrome is made clinically. Upper abdominal ultrasound demonstrates ascites and should detect pleural effusions. Pelvic ultrasound demonstrates the presence of a well demarcated adnexal mass without increased vascularity. Chest x-ray may be used to confirm the presence of a pleural effusion. Other imaging modalities like MRI or CT can be considered to exclude metastatic disease prior to treatment. 
The cytological exam of the ascitic and pleural liquid in patients with ovarian tumors should be performed in order to differentiate between reactive processes and tumor spread. Although the detection of malignant cells is a marker of malignant disease and a sign of poor prognosis, the benign effusions don't affect neither the stage of the disease nor the prognosis of the patient.13 Review of reported cases of pseudo-Meigs syndrome shows that pleural fluid in these patients contains reactive mesothelial cells with no neoplastic cells25.Some authors emphasize that an ovarian mass with pleural and abdominal effusion doesn't always represent an advanced stage malignancy, not even in presence of high serum levels of CA-125 23,24.

CA-125 antigen is a tumor marker associated with ovarian carcinoma. Nevertheless, elevated

levels of CA-125 have also been reported in the literature for Meigs or pseudo-meigs syndrome, although levels above $1,000 \mathrm{U} / \mathrm{mL}$ were rarely reported.[17,18] Lin et al. used immunohistochemical techniques to localize CA-125 expression, and they found that it is expressed by mesothelium rather than the fibroma .[19]. Case reviews have shown that higher levels of CA-125 are associated withhigher volume of ascites but size of tumor was not linearly correlated with CA-125 levels20.

The definitive diagnosis of Meigs' syndrome is usually postoperative with resolution of ascites and pleural effusions, and histological confirmation of the tumour.

Serous cystadenomas are diagnosed by histomorphologic examination, by pathologists. Grossly, they are, usually, small unilocular cysts that contain clear, straw-coloured fluid. However, they may sometimes be multilocular. Microscopically, the cyst lining consists of a simple epithelium, whose cells may be either.[12] .

- be columnar and tall and contain cilia, resembling normal tubal epithelium

- be cuboidal and have no cilia, resembling ovarian surface epithelium

Medical care of patient with Meigs' or pseudo-Meigs syndrome involves paracentesis and thoracentesis for ascites and pleural effusion respectively. The treatment of choice is exploratory laparotomy with surgery and staging. Frozen section of ovarian mass is performed to confirm the benign nature of the mass. In women of reproductive age, unilateral salpingo-oophorectomy is the treatment of choice, whereas in post-menopausal women treatment is total abdominal hysterectomy with bilateral salpingo-oophorectomy.

Removal of the tumor will ultimately result in resolution of ascites, pleural effusion, and normalization of CA-125 in Meigs' and pseudoMeigs' syndrome .[5,22]. Life expectancy of patients after surgical removal of the tumor is the same as the general population.

Conclusion: In this case report, we presented a patient who had pleural effusions, ascites, normal CA-125 and right adnexal mass. An awareness of benign lesions of the pelvis with associated adverse features is important for both clinicians and their imaging partners to limited patient anxiety and direct appropriate treatment. Biochemical markers like CA125 have limited diagnostic capabilities and their real value lies in cancer treatment surveillance.

\section{Conflict of Interest:}

The authors have not conflict of interest to declare for this work.

\section{Compliance with ethical standards}

Written informed consent was obtained from the patients for publication of this case report and any accompanying images.

\section{Funding source:}

None.

\section{References}

1. Lurie S. Meigs' (2000 ) syndrome: the history of the eponym. Eur J Obstet Gynecol Reprod Biol ; 92: 199-204.

2. Lallemand A. (1896) Contribution a'l'étude des fibromes de l'ovaire. Thése pourle doctorat en médecine. Paris;. No.285.

3. Meigh JV, Cass JW. Fibroma of the ovary with ascites and hydrothorax: With a report of seven cases. Am J Obstet Gynecol 1937; 33: 249-67.

4. Rhoads JE, Terrell AW.( 1684.) Ovarian fibroma with ascites and hydrothorax (Meigs syndrome): a case. JAMA 1937; 109:

5. Meigs JV. Fibroma1954) of the ovary with ascites and hydrothorax- Meigs syndrome. Am J Obstet Gynecol ; 67: 96285.

6. Peparini N, Chirletti P. (2009)Ovarian malignancies with cytologically negative pleural and peritoneal effusions: demons' or meigs' pseudo-syndromes? Int J Surg Pathol ; 17: 396-7.

7. Martin F, Brouche S, Haidar A. A propos d'un cas avec tumeur ovarienne de la granulosa. Rev Pneumol Clin 1990; 46: 123-24.

8. Shih JA, Garrett LA, Carbo AR: Meigs' syndrome: a sheep in Wolf's clothing . Am J Med. 201 132:803-804.

9. Brun JL: Demons syndrome revisited: a review of the literature . Gynecol Oncol. 2007, 105:796-800.

10. Human Reproduction. University of Utah Medpath.

11. Cheng, EJ.; Kurman, RJ.; Wang, M.; Oldt, R.; ( 2004) Wang, BG.; Berman, DM.; Shih, IeM. (Jun). "Molecular genetic analysis of ovarian serous cystadenomas". Lab Invest. 84 (6): 778-84.

12. Bhatla N. Jeffcoate's ( 2001) Principles of Gynecology. International edn. Revised, and updated from the 5th edn. Arnold publishers, London:523-4.

13. Hernandez E, Atkinson B. Clinical Gynecologic Pathology Philadelphia. W.B. Saunders Company. 1996:521.

14. Ishiko O, Yoshida H, Sumi T, Hirai K, Ogita S: ( 2001) Vascular endothelial growth factor levels in pleural and peritoneal fluid in Meigs' syndrome. Eur J Obstet Gynecol Reprod Biol.,98:129-130.

15. Krenke R, Maskey-Warzechowska M, Korczynski P, ZielinskaKrawczyk M, Klimiuk J, Chazan R, et al. ( 2015) Pleural effusion in Meigs' Syndrome-transudate Or Exudate?: Systematic review of the literature. Medicine (Baltimore) 94:e2114.

16. Handler CE, Fray RE, Snashall PD. ( 1982) Atypical Meigs' syndrome. Thorax;37:396-7.

17. Timmerman D, Moerman P, Vergote I: Meigs'( 1995) syndrome with elevated serum CA 125 levels:two case reports and review of the literature. Gynecol Oncol., 59:405-408.

18. Benjapibal M, Sangkarat S, Laiwejpithaya S, Viriyapak B, Chaopotong P, Jaishuen A( 2009): Meigs' syndrome with elevated serum CA125: case report and review of the literature. Case Rep Oncol, 2:61-66.

19. Lin JY, Angel C, Sickel JZ: ( 1992) Meigs syndrome with elevated serum CA 125. Obstet Gynecol.,80:563-566.

20. Liou JH, Su TC, Hsu JC: ( 2011) Meigs' syndrome with elevated serum cancer antigen 125 levels in a case of ovarian sclerosing stromal tumor. Taiwan J Obstet Gynecol, 50:196-200.

21. Shahrzad Ehdaivand, ( 2017) M.D. "Ovary tumor - serous tumors - Serous cystadenoma / adenofibroma / surface papilloma". Pathology Outlines. Topic Completed: 1 June 2012. Revised: 5 March 22. Yadav S, Tomar R, Verma N, Khurana N, Triathi R: Struma ovarii with pseudo-Meigs' syndrome and raised cancer antigen-125 levels masquerading as an ovarian carcinoma: case report and literature review. Sultan Qaboos Univ Med J, 17:e229e233. 
22. Santangelo M, Battaglia M, Vescio G, Sammarco G, Gallelli G, Vetere A, Soommella L, Triggiani ( 2000) E. Meigs's syndrome: its clinical picture and treatment. Ann Ital Chir 2000; 71(1): 1159.

23. Rozier R, Berger A, Cugnenc ( 1998) PH. Meigs's syndrome: is it possible to make a preoperative diagnosis? J Gynecol Obstet Biol Reprod; 27(5): 517-22.

24. Dunn JS Jr, Anderson CD, ( 1998) Method MW, Brost BC: Hydropic degenerating leiomyoma presenting as pseudo-Meigs syndrome with elevated CA 125. Obstet Gynecol, 92:648-649.

To Submit Your Article Click Here: Submit Article

DOI: $10.31579 / 2578-8965 / 056$
Ready to submit your research? Choose Auctores and benefit from:

* fast, convenient online submission

* rigorous peer review by experienced research in your field

* rapid publication on acceptance

* authors retain copyrights

* unique DOI for all articles

* immediate, unrestricted online access

At Auctores, research is always in progress.

Learn more www.auctoresonline.org/journals/obstetrics-gynecologyand-reproductive-sciences 